\title{
One-year outcome of laparoscopic sleeve gastrectomy in morbidly obese adolescents
}

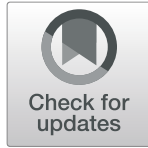

\author{
Mohamed El ghazeery ${ }^{*}$ (D), Mohamed Elsawaf, Mohamed Ashour, Mohamed Metwaly and Mohamed Hashish
}

\begin{abstract}
Background: Adolescent obesity is an important health issue. Non-surgical weight management programs, even the most aggressive, have shown modest weight reduction results. Laparoscopic sleeve gastrectomy (LSG) is gaining reliability as a low surgical risk bariatric procedure with proper efficiency for this age group. The aim of this study was to present our initial experience with LSG in morbidly obese adolescents and to report short-term clinical and metabolic outcome.

Results: Mean age was 16.43 years, and mean preoperative weight and body mass index (BMI) were $132.68 \mathrm{~kg}$ and 48.90 respectively. Mean excess weight loss (EWL) was $54.11 \mathrm{~kg} 1$ year after LSG, corresponding to $74 \mathrm{EWL} \%$ as well as mean BMI loss (BML) of 19.89. LSG improved fatty infiltration of the liver in $75 \%$ of cases and other comorbidities in $100 \%$ of patients.
\end{abstract}

Conclusions: LSG proved to be a safe procedure with significant short-term clinical and metabolic success for adolescent obesity.

Keywords: Adolescent obesity, Bariatric, Laparoscopy, Sleeve gastrectomy

\section{Background}

Adolescent obesity is a progressive disease causing significant morbidity [1-3]. It is associated with serious co-morbidities, such as hypertension, diabetes mellitus, non-alcoholic fatty liver disease (NAFLD), and dyslipidemia $[4,5]$. Moreover, poor body image, reduced quality of life, and psychological impacts are still grave issues [6-9]. Non-surgical management rarely results in sustained weight reduction or resolution of these comorbidities [3].

There is still a controversial consensus regarding ideal bariatric surgery for each age group especially for adolescents. Laparoscopic sleeve gastrectomy (LSG) is gaining reliability as a low surgical risk bariatric procedure with proper efficiency for this age group. The aim of this study was to present our initial experience with LSG in morbidly obese adolescents and to report feasibility and short-term clinical results as a primary outcome and

\footnotetext{
* Correspondence: mohmed.elghazeery@med.tanta.edu.eg;

elghazeery@hotmail.com

Pediatric Surgery Unit, Faculty of Medicine, Tanta University, Tanta, Egypt
}

metabolic changes and comorbidity resolution as a secondary outcome.

\section{Methods}

This was a prospective study which included 35 morbidly obese adolescents aged between 12 and 19 years. Their body mass indices were above 99th percentile for age and sex with or without comorbidities. Patients and their parents were counseled about potentially available surgical procedures (LSG, gastric band, and Roux-en-Y gastric bypass) including pros and cons, possible outcomes, complications, and optimum postoperative lifestyle changes. All patients underwent comprehensive evaluations by multidisciplinary team including pediatric endocrinologist, nutritionist, and psychologist preoperatively. All obese adolescents who failed to achieve significant weight loss (10\% of initial weight at 6 months) through non-surgical treatment were indicated to LSG and included in our study. We excluded patients with hiatal hernia, GERD or had previous open upper GI surgery; being pregnant, lactating, or having secondary
Springer Open (c) The Author(s). 2021 Open Access This article is licensed under a Creative Commons Attribution 4.0 International License, which permits use, sharing, adaptation, distribution and reproduction in any medium or format, as long as you give appropriate credit to the original author(s) and the source, provide a link to the Creative Commons licence, and indicate if changes were made. The images or other third party material in this article are included in the article's Creative Commons licence, unless indicated otherwise in a credit line to the material. If material is not included in the article's Creative Commons licence and your intended use is not permitted by statutory regulation or exceeds the permitted use, you will need to obtain permission directly from the copyright holder. To view a copy of this licence, visit http://creativecommons.org/licenses/by/4.0/. 
obesity; or having any medical or psychological issues preventing commitment to postoperative regimens. An informed consent was obtained from parents with assent from patients less than 18 years or directly from patients more than 18 years to be enrolled in the study and possible publication. Our institutional ethical committee approval was obtained before starting the study (No: 30279/05/15). All candidates underwent LSG at our University Hospital between August 2015 and August 2017. Their medical records including anthropometric measurements were contemporaneously reviewed, and all data were collected in Excel sheet. Baseline, operative, and follow-up data were thoroughly reviewed, analyzed, and summarized.

Routine preoperative esophagogastroduodenoscopy (OGD), helicobacter test (antigen in stool), and echocardiogram to evaluate left ventricle hypertrophy were obtained in all cases. Clinical and laboratory assessments including total cholesterol (TC), low-density lipoprotein (LDL), high-density lipoprotein (HDL), triglycerides (TG) $(\mathrm{mg} / \mathrm{dL})$, oral glucose tolerance test (OGTT), glycated hemoglobin (HbA1c), transaminases, and abdominal ultrasound for evaluation of hepatic fatty infiltration were obtained preoperatively and 6 and 12 months postoperatively in all cases.

The following variables were used to orderly define comorbidities: pre-diabetes (fasting glucose FG $\geq 100$ and $<126 \mathrm{mg} / \mathrm{dL}$ or OGTT $\geq 140$ and $<200 \mathrm{mg} / \mathrm{dL}$ ), type 2 diabetes mellitus (T2D) (FG $\geq 126 \mathrm{mg} / \mathrm{dL}$ or OGTT $\geq$ $200 \mathrm{mg} / \mathrm{dL}$ or glycated hemoglobin $\mathrm{Hb} \geq 6.5 \%$ ), dyslipidemia $(\mathrm{TC}>200$ or $\mathrm{LDL}>130$ or $\mathrm{HDL}<40$ or $\mathrm{TG}>130$ $\mathrm{mg} / \mathrm{dL}$ ), and hypertension was diagnosed when systolic and/or diastolic BP greater than the 95th percentile for age, sex, and height.

\section{Surgical procedure}

Standard 5-port LSG was done using French position with the surgeon standing between the patient's legs. After devascularization of the greater curve and complete fundus mobilization using bipolar sealing device (LigaSure ${ }^{\mathrm{Tw}}$, Medtronic, USA), gastrectomy over size $36 \mathrm{fr}$ bougie starting $4 \mathrm{~cm}$ proximal to pylorus was done using Echelon EndoGIA stapler (Johnson and Johnson). No second layer (inverting lambert sutures) was performed; titanium clips were used to stop bleeding at the staple line when indicated. Fixation of the gastric sleeve to the pre-pancreatic fascia using two $2 / 0$ monofilament sutures was done to prevent twist. A drain was inserted in all cases. Detailed surgical descriptions, including all steps, intraoperative mishaps, and/or complications, were recorded.

\section{Postoperative management}

Patients started oral intake $12 \mathrm{~h}$ postoperatively and were discharged 2 days postoperatively once tolerating adequate oral fluids, their pain was controlled, and they were ambulating easily. Postoperatively, patients were advised to start liquid diet for 2 weeks, then soft diet for 2 weeks, and solid diet after 4 weeks by gradual excess in food texture. All patients discharged on multivitamins with calcium and vitamin D daily; vitamins B1, 6, and 12 intramuscular weekly; and proton pump daily for 6 months. Patients were scheduled to attend our outpatient clinic 2, 6 weeks after surgery, and then 3, 6, and 12 months, then annually to monitor weight loss, appetite, dysphagia or food intolerance, eating behavior, comorbidity status, and any complications. Postoperatively, physical activity was allowed, and our cases were followed for 1 year.

Measurements such as weight $(\mathrm{kg})$, height $(\mathrm{m})$, and BMI $\left(\mathrm{kg} / \mathrm{m}^{2}\right)$ as well as waist circumference WC $(\mathrm{cm})$ were recorded in every visit. Excess weight $(E W)=$ (preoperative weight-ideal weight) was measured using weight values above 85th percentile for age and sex, and excess weight loss ratio (EWL) \%= (preoperative weight -current weight/EW) $\times 100$. EBMI loss (excess body mass index loss) and body mass index loss ratio (BML\%) were measured, compared with preoperative data, and reported in all cases. Follow-up of comorbidity resolution was recorded.

\section{Statistical analysis}

Statistical analysis of the present study was conducted, using the mean, standard deviation, ANCOVA test, and chi-square test using the SPSS ${ }^{\bullet}$ software package version 24. (IBM. USA, Chicago). We used chi-square to evaluate all qualitative data including percentages and student $\mathrm{T}$ test to evaluate mean and SD.

\section{Results}

Current study included 35 patients: 11 males and 24 females. Age ranged from 12 to 19 years with mean age of $16.43 \pm 2.32$ years. Ten patients were from 12 to 14 years and 25 patients from 16 to 19 years. Mean preoperative weight and height were $132.68 \pm 32.82 \mathrm{~kg}$ and $163.68 \pm 11.05 \mathrm{~cm}$ respectively whereas mean preoperative BMI was $48.90 \pm 8.89 \mathrm{~kg} / \mathrm{m}^{2}$.

Mean operative time was $101.75 \pm 13.89 \mathrm{~min}$. There were no conversions or operative complications including inadvertent injury to any organ, bleeding, stapler misfiring, narrow sleeve, anteroposterior disproportion leading to sleeve twist, or any other complication. Hospital stay was 2 days, without readmissions or deaths.

Complications included 3 patients with mild wound infection, $5(14.3 \%)$ patients with hypocalcemia 2 months postoperatively but was corrected with supplementation within 2 months, one patient complaining of hair loss and had decreased serum zinc 3 months postoperatively, and $8(22.9 \%)$ patients that had symptoms 
suggestive of GERD (vomiting, heart burn, and dyspepsia) 2 months postoperatively and were relieved with medical treatment (proton pump inhibitor, prokinetic drugs) for 2 months. We had no leakage and no mortality in our series.

Mean postoperative weight values with statistically significant changes along 1 year are shown in Table 1 , and mean EWL was $22.87,39.19$, and $54.11 \mathrm{~kg}$ in 3,6 , and 12 months post-LSG respectively. Moreover, mean excess weight loss ratio (EWL\%) along 1 year is illustrated in Fig. 1.

Mean preoperative BMI was $48.90 \pm 8.89 \mathrm{~kg} / \mathrm{m}^{2}$, and mean BMI excess was $22.23 \mathrm{~kg} / \mathrm{m}^{2}$. Mean postoperative BMI and mean EBMIL with statistically significant results 1-year post-LSG are illustrated in Fig. 2.

Mean preoperative waist circumference (WC) and postoperative WC loss of our patients along 1 year are shown in Fig. 3.

We succeeded to have $2(5.7 \%)$ and 11 (31.4\%) nonobese patients (BMI less than $25 \mathrm{~kg} / \mathrm{m}^{2}$ or less than 85th percentile) on 6 and 12 months respectively out of 35 obese patients as shown in Fig. 4, and this was statistically significant by comparing percentage of non-obese in relation to preoperative ones. Preoperative comorbidities and postoperative resolution are demonstrated in Table 2.

\section{Discussion}

Considering low response to non-surgical treatment and impaired quality and expectancy of life in morbidly obese adolescents, bariatric surgery seems to be the ideal management hope. However, long-term impacts of surgery, such as growth and psychological outcome, are not fully understood till now.

Only few literatures had addressed LSG in adolescent obesity. Assessment of different comorbidities and metabolic derangements before and after LSG illustrates its effect and changes the procedure from being just weight reduction surgery to metabolic one. In the present study, we evaluated clinical and metabolic parameters for 35 morbidly obese adolescents before and after LSG during a period of 12 months: 24 females and 11 males. Different parameters as age, weight, $\mathrm{BMI}, \mathrm{WC}$, and comorbidities

Table 1 Postoperative weight changes

\begin{tabular}{llll}
\hline Weight & Range & Mean \pm SD & $P$ value \\
\hline Preoperative & $85.6-189$ & $132.68 \pm 32.82$ & \\
2 weeks & $79-178$ & $121.80 \pm 31.35$ & 0.203 \\
3 months & $75-160$ & $109.78 \pm 26.64$ & $0.008^{*}$ \\
6 months & $64.58-142$ & $93.79 \pm 22.69$ & $0.001^{*}$ \\
12 months & $52.1-119$ & $78.56 \pm 17.82$ & $0.001^{*}$ \\
\hline
\end{tabular}

$P$ value indicates statistical significance

$S D$ standard deviation

*symbol indicate statistical significance including hypertension, DM, SAS, and dyslipidemia of our cases as well as reported obese adolescents who underwent LSG in literature are shown in Table 3. We also reported that 9 of 35 (25.7\%) patients in our case series had PCO including irregular menses and hirsutism as an important comorbidity associated with morbid obesity in adolescent girls that was not reported before in literature.

Mean operative time in our study was $101.75 \mathrm{~min}$ which is close to that reported by Park et al. (108 min) [11], and slightly more than Alqahtani et al. [10]; they reported $84 \mathrm{~min}$, while it was significantly lower than reported by Franco et al. (256 min) [14]. We did not have any intraoperative complications as bowel, organ, or vascular injury; inadvertent bleeding from the gastric remnant; or mishaps as stapler mechanical failure. The technically demanding key operative steps included complete fundal dissection, antral measurements, and first and last stapler firings. Mean hospital stay in our study was 2 days which was closely similar or lower than most studies. However, it was more than Park et al.'s [11] study which was 1 day. Short operative time reflects feasibility and reproducibility of the procedure, while short hospital stay confirms its safety.

Postoperatively, we encountered minor complications as mild wound infection in $3(8.6 \%)$ cases and mild temporary de novo reflux manifestations in $8(22.9 \%)$ patients which was detected between the second and third month postoperatively and resolved within 2 months of medical treatment. We think we had temporary reflux due to leaving adequate antrum preventing formation of high-pressure zone at the GE junction, in addition to stapling $0.5 \mathrm{~cm}$ from the angle of His preserving the sling fibers responsible for antireflux mechanism. Also, pouch-related complications such as stenosis, spiral sleeve, or twist are very important causes of postoperative vomiting and reflux; these were avoided in our patients by sticking to critical operative tricks. The first stapler was done from left working port parallel to the lesser curvature avoiding being perpendicular on incisura causing its narrowing, traction from devascularized greater curvature during stapling avoiding excess removal from one surface of the stomach more than other one, and fixing the pouch with 2 hypnotic stitches to the peripancreatic fascia preventing sleeve twist.

Hypocalcemia occurred in $5(14.3 \%)$ patients that was detected 3 months after LSG and corrected within 2 months with calcium with vitamin D supplementation, and zinc deficiency in one case 3 months postoperatively corrected in 3 months; both of them were mostly due to lack of compliance of patients to take multivitamins and stick to nutritional instructions. Aridi et al. [12] reported one case of wound infection. Alqahtani et al. [10] had wound infection in 2 cases and gastroesophageal disease in 3 cases. Franco et al. [14] reported one case of iron 


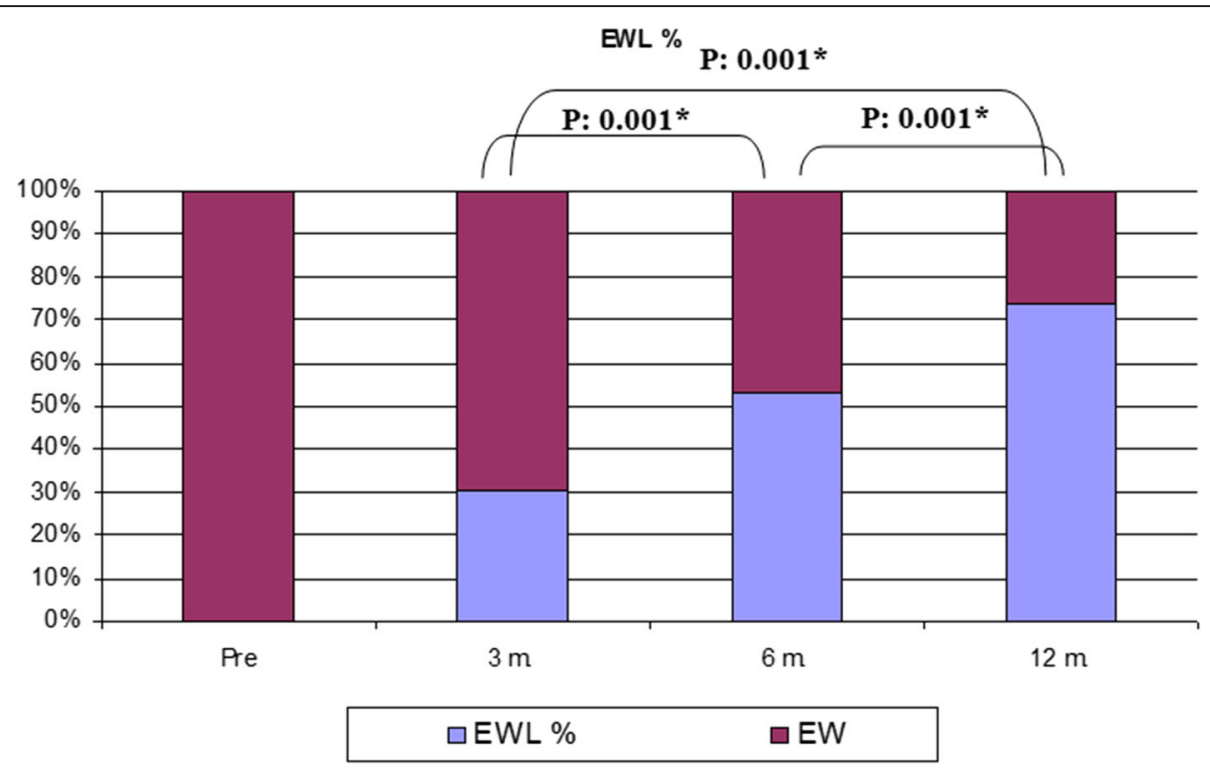

Fig. 1 EWL and EWL\% changes

deficiency. To our minds, antral length of $4 \mathrm{~cm}$ and vitamin B complex supplementation are two important factors; both facilitate adequate iron absorption and prevented its deficiency in our series.

In our study, mean weight 1 -year post-LSG was 78.56 $\mathrm{kg}$ which is lower than mean weight of Aridi et al. [12] $80.3 \mathrm{~kg}$ and Dargan et al. [13] $94.1 \mathrm{~kg}$. We succeeded to have mean EWL of $54.11 \mathrm{~kg}$ after 1-year post-LSG which is higher than all literature, Alqahtani et al. [10] $42.7 \mathrm{~kg}$, Franco et al. [14] $34.5 \mathrm{~kg}$, and Dargan et al. [13] $39.1 \mathrm{~kg}$.

Mean EWL\% was 74.08\% 1-year post-LSG which is only lower than Aridi et al. [12] (90.1\%), while higher than other literature including Alqahtani et al. [10] (61.3\%), Franco et al. [14] (60\%), Dargan et al. [13]

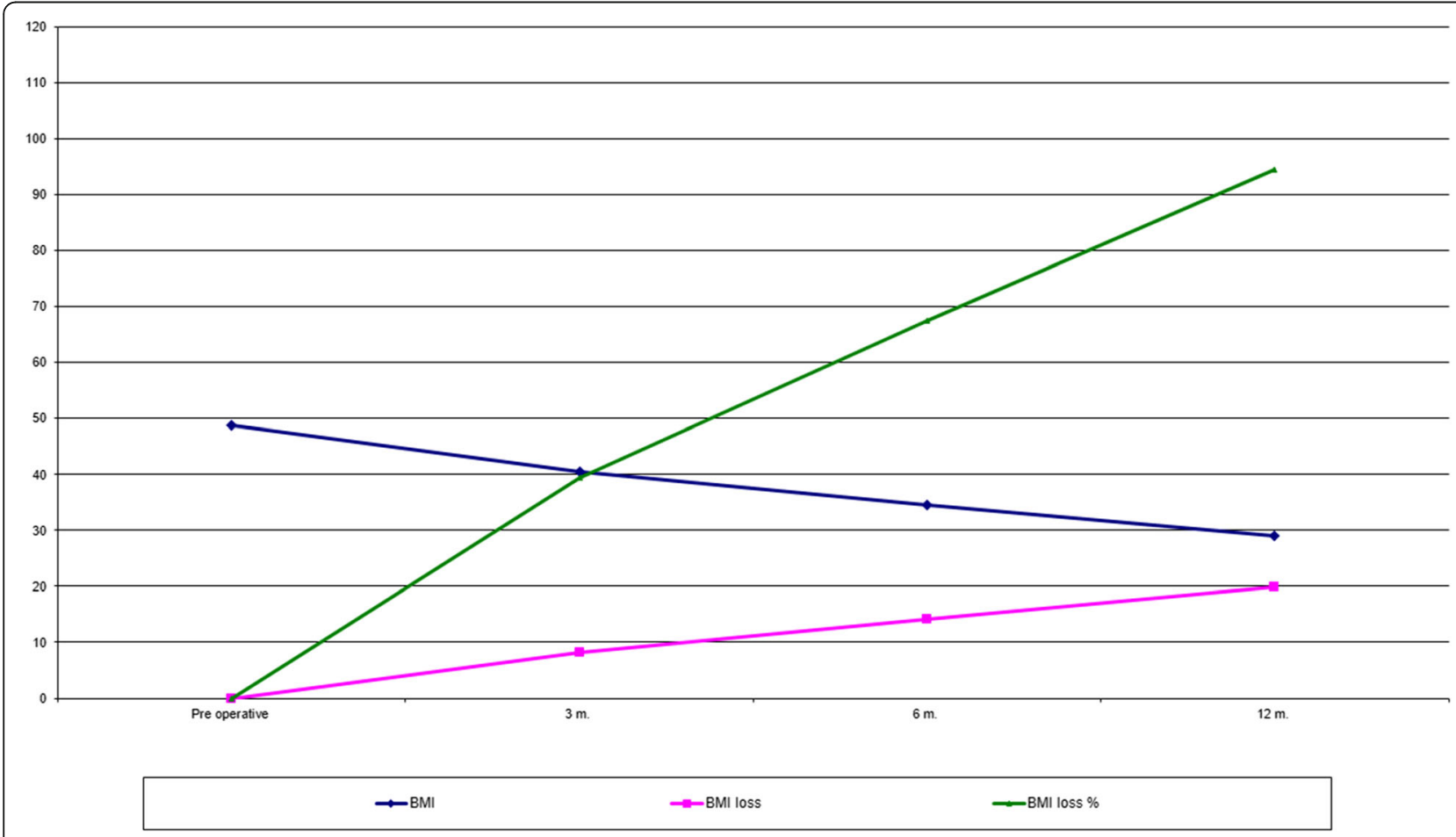

Fig. 2 Simultaneous changes of BMI, BML, and BML\% of our patients 


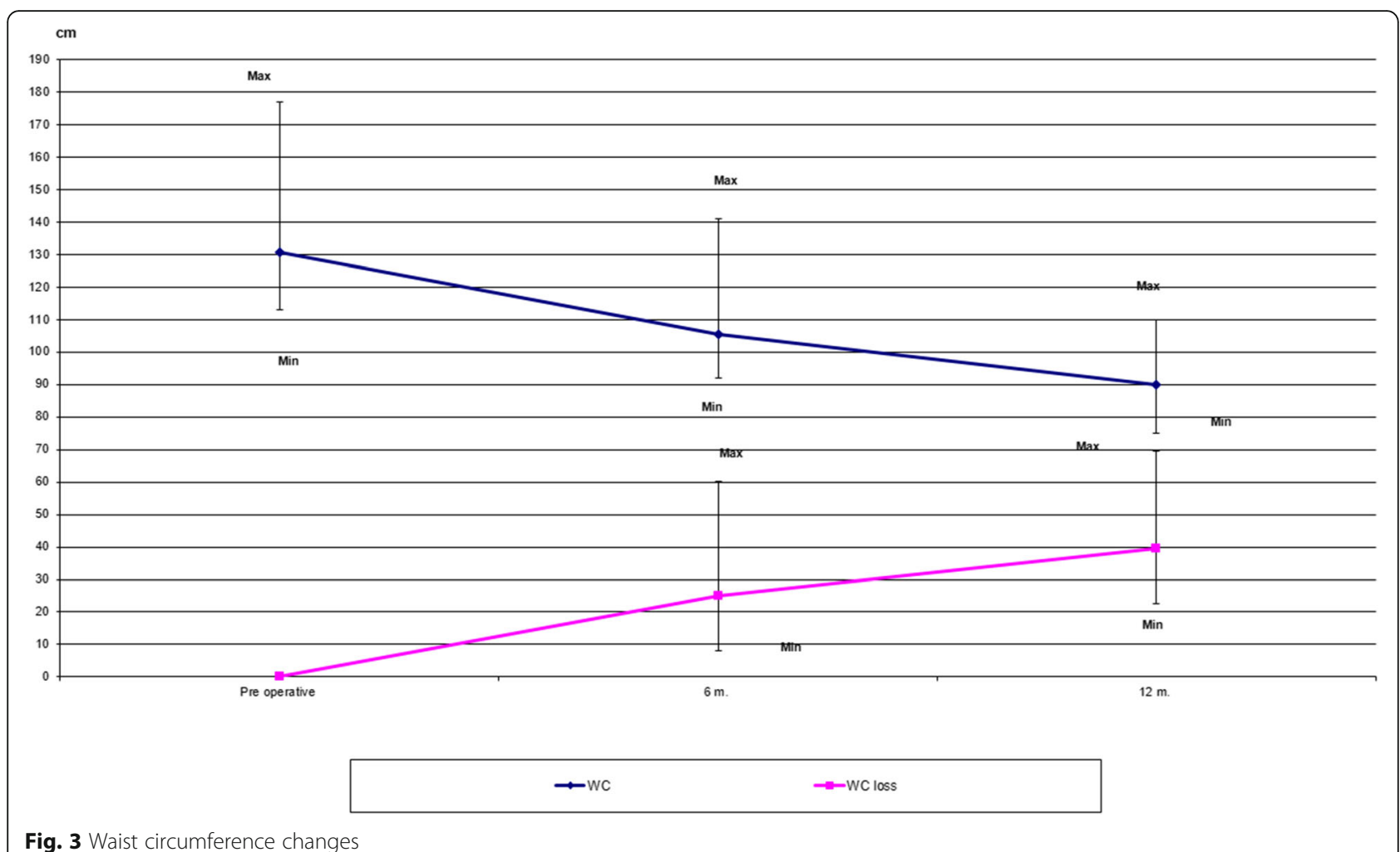

(64\%), and Park et al. [11] (67.6\% after 1 year). After 1year post-LSG, EWL\% was maintained above the expected value (50 to $70 \%$ ) according to Reinhold criteria by sticking to close follow-up with continuous nutritional and exercise support for all our teens $[15,16]$.
In our study, mean 1-year postoperative BMI was $29.01 \mathrm{~kg} / \mathrm{m}^{2}$ which is slightly higher than Aridi et al. [12] $\left(28.4 \mathrm{~kg} / \mathrm{m}^{2}\right)$. However, Alqahtani et al. [10] and Dargan et al. [13] showed higher mean BMI after 1 year, 32.4 and $31.2 \mathrm{~kg} / \mathrm{m}^{2}$ respectively. Mean BMI excess was

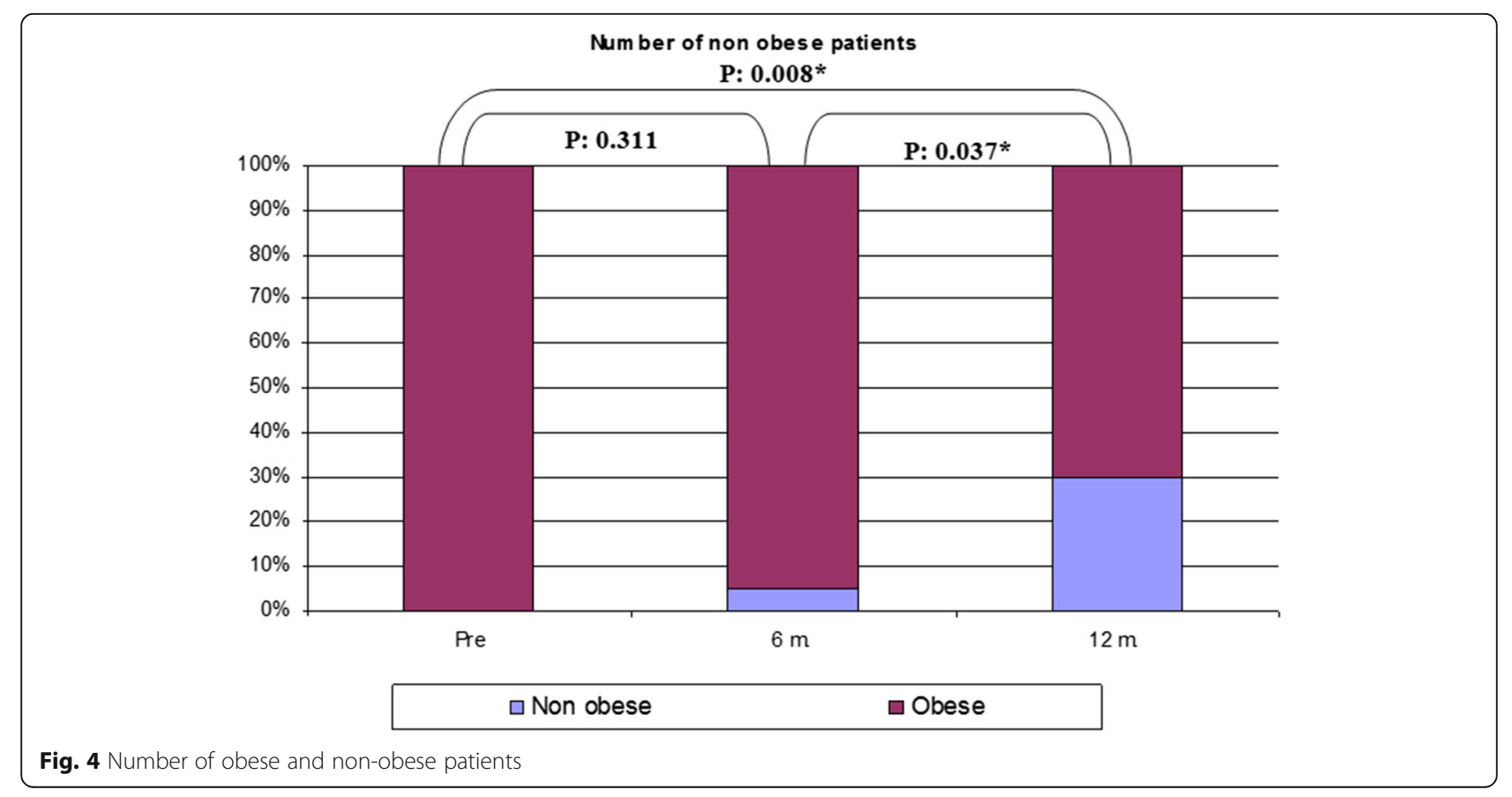


Table 2 Comorbidity resolution among patients

\begin{tabular}{|c|c|c|c|c|c|c|}
\hline \multirow[t]{2}{*}{ Comorbidities } & \multicolumn{2}{|c|}{ Preoperative } & \multicolumn{2}{|c|}{6 months } & \multicolumn{2}{|c|}{12 months } \\
\hline & $\mathbf{N}$ & $\%$ & $\mathrm{~N}$ & $\%$ & $\mathbf{N}$ & $\%$ \\
\hline HTN (MeS) & 22 & 63 & 9 & 26 & 0 & 0 \\
\hline TG (MeS) & 21 & 60 & 7 & 20 & 0 & 0 \\
\hline (HDL) (MeS) & 9 & 26 & 4 & 11 & 0 & 0 \\
\hline Cholesterol & 2 & 6 & 0 & 0 & 0 & 0 \\
\hline Pre-diabetic (MeS) & 23 & 66 & 5 & 14 & 0 & 0 \\
\hline (NAFLD) & 28 & 80 & 16 & 46 & 7 & 20 \\
\hline (SAS) & 16 & 46 & 4 & 11 & 0 & 0 \\
\hline$(\mathrm{PCO})$ & 9 & 26 & 4 & 11 & 2 & 6 \\
\hline
\end{tabular}

$N$ refers to number

MeS metabolic syndrome parameter, HTN hypertension, TG triglyceride, HDL high-density lipoprotein, NAFLD nonalcoholic liver disease, SAS sleep apnea syndrome, PCO polycystic ovary

$22.23 \mathrm{~kg} / \mathrm{m}^{2}$ among our cases. EBMIL and EBMIL\% were not routinely reported in literature. In our study, mean EBMIL was $19.89 \mathrm{~kg} / \mathrm{m}^{2} 1$-year post-LSG which is markedly higher than Franco et al. [14] $\left(12.3 \mathrm{~kg} / \mathrm{m}^{2}\right)$. Also, we report EBMIL\% of $94.64 \% 1$ year postoperatively which is markedly higher than Alqahtani et al. [10] (68.9\%).

One year postoperatively, mean WC in our study was $89.95 \mathrm{~cm}$ which is lower than Franco et al. [14] $(108.4 \mathrm{~cm})$ and Dargan et al. [13] $(98.3 \mathrm{~cm})$. Regarding resolution of obesity-related comorbidities after 1-year follow-up, we could demonstrate 100\% hypertension resolution, while Aridi et al. [12], Alqahtani et al. [10], Park et al. [11], and Franco et al. [14] studies showed its resolution in $5 / 8$ (62.5\%), 27/36 (75\%), 1/2 (50\%), and 10/13 (76.9\%), respectively. In our study and in Alqahtani et al.'s [10], prediabetic patients showed $100 \%$ resolution 1 year postoperatively.

Also, SAS disappeared in $100 \%$ of our cases and in Park et al. [11] within 1 year postoperatively. On contrary, SAS resolution in Aridi et al. [12] and Alqahtani et al. [10] was $80 \%$ and $90.9 \%$ respectively. Uniquely in our study, we had PCO in 9 cases, 5 of them improved within 6 months and 2 after 1 year showing regular menses, improvement of hirsutism, and disappearance of ovarian cysts. This was not reported or discussed in other literature.

We were also able to demonstrate complete resolution of dyslipidemia in all our cases after 1-year post-LSG. While dyslipidemia resolution in Aridi et al. [12] was $58.3 \%$, Alqahtani et al. [10] was $70 \%$, Park et al. [11] was $53.8 \%$, and Franco et al. [14] was $90.5 \%$.

To summarize our results, we could demonstrate significant resolution of obesity-associated comorbidities in almost all adolescent cases in our study with adequate weight loss 12 months post-LSG.

\section{Conclusion}

Upon our initial experience, we could report that LSG is an efficient and safe bariatric procedure offering significant weight reduction and almost resolution of obesityrelated comorbidities in adolescent obesity. Ideal and meticulous selection of patients, sticking to a standardized surgical approach, and follow-up are necessary for optimal results. Studies that evaluate quality of life and long-term impacts are needed, especially the psychological impact of bariatric surgery in adolescents.

Table 3 The ages, numbers, and preoperative parameters of the reported adolescent obese patients

\begin{tabular}{|c|c|c|c|c|c|c|c|}
\hline & & \multicolumn{6}{|l|}{ Study } \\
\hline & & Alqahtani et al. [10] & Park et al. [11] & Aridi et al. [12] & Dargan et al. [13] & Franco et al. [14] & Our study \\
\hline \multirow[t]{2}{*}{ Age } & Range & $5-21$ & $14-20$ & $11-21$ & $16.8-19.8$ & $14-19$ & $12-19$ \\
\hline & Mean & 13.9 & 19 & 18.6 & 19.1 & 16.89 & 16.43 \\
\hline Number of patients & & 108 & 14 & 119 & 13 & 22 & 35 \\
\hline Preoperative WT (kg) & Mean & 120.8 & 117.6 & 117.9 & 133.6 & 128.5 & 132.68 \\
\hline Preoperative BMI $\left(\mathrm{kg} / \mathrm{m}^{2}\right)$ & Mean & 50.7 & 40.2 & 41.9 & 46.2 & 46.5 & 48.9 \\
\hline \multicolumn{2}{|l|}{ Mean preoperative WC (cm) } & & & & 130.8 & 133.6 & 130.5 \\
\hline \multicolumn{2}{|l|}{ HTN } & $39 / 108$ & $2 / 14$ & $8 / 119$ & & $13 / 22$ & $22 / 35$ \\
\hline \multicolumn{2}{|l|}{ Prediabetes } & $14 / 108$ & & & & & $23 / 35$ \\
\hline \multicolumn{2}{|l|}{ Preoperative SAS } & $36 / 108$ & $4 / 14$ & $5 / 119$ & & & $16 / 35$ \\
\hline \multicolumn{2}{|l|}{ Dyslipidemia } & $52 / 108$ & $13 / 14$ & $12 / 119$ & & $21 / 22$ & $2 / 35$ \\
\hline
\end{tabular}




\section{Abbreviations}

WLS: Weight loss surgery; LSG: Laparoscopic sleeve gastrectomy; BMI: Body mass index; EWL: Excess weight loss; EWL\%: Excess weight loss ratio; NAFL D: Non-alcoholic fatty liver disease; US: United States; WC: Waist circumference; EW: Excess weight; EBMl: Excess body mass index; BML\%: Body mass index loss ratio; TC: Total cholesterol; LDL: Low-density lipoprotein; HDL: High-density lipoprotein; OGTT: Oral glucose tolerance test; A1C: Glycated hemoglobin; OGD: Esophagogastroduodenoscopy; FG: Fasting glucose; T2D: Type 2 diabetes mellitus; Hb: Hemoglobin; TG: Triglyceride; BP: Blood pressure; EBMIL: Excess body mass index loss; EBMIL\%: Excess body mass index loss ratio; WC: Waist circumference; PCO: Polycystic ovary; SAS: Sleep apnea syndrome; GERD: Gastroesophageal reflux disease; MeS: Metabolic syndrome; FBS: Fasting blood sugar

\section{Acknowledgements}

To all coauthors

\section{Local institutional review board approval code} 30279/05/15

\section{Authors' contributions}

MAE: data collection and a major contributor in writing the manuscript. MM: general supervisor of research group. MA: academic background support. MIE: the main mentor and editor of the manuscript. $\mathrm{MH}$ : analyzed and interpreted the patient data. The authors read and approved the final manuscript.

\section{Funding}

Not applicable

\section{Availability of data and materials}

Patients accepted availability of their confidential data on computer system.

\section{Declarations}

\section{Ethics approval and consent to participate}

Informed written consent which was accepted from local Institutional Review Board affiliated to Faculty of Medicine, Tanta University, was obtained from parents with assent from patients younger than 18 years or directly from patients older than 18 years to be included in the study and for operation in addition to obtaining appropriate institutional ethics committee approval.

\section{Consent for publication}

Written consent which was accepted from local Institutional Review Board affiliated to Faculty of medicine was obtained from study participants for publication.

\section{Competing interests}

The authors declare that they have no competing interests.

Received: 10 June 2020 Accepted: 19 May 2021

Published online: 02 August 2021

\section{References}

1. Velhote MCP, Damiani D, Santoro S. Bariatric surgery in pediatrics - is it time? J Pediatr Endocrinol Metab. 2007;20(7):751-61. https://doi.org/10.151 5/jpem.2007.20.7.751

2. Whitlock EP, O'Connor EA, Williams SB, Beil TL, Lutz KW. Effectiveness of weight management interventions in children: a targeted systematic review for the USPSTF. Pediatrics. 2010;125(2):e396-418. https://doi.org/10.1542/ peds.2009-1955.

3. Treadwell JR, Sun F, Schoelles K. Systematic review and meta-analysis of bariatric surgery for pediatric obesity. Ann Surg. 2008;248(5):763-76. [PubMed: 18948803]. https://doi.org/10.1097/SLA.0b013e31818702f4

4. Kimm SY, Barton BA, Obarzanek E, McMahon R, Kronsberg SS, Waclawiw $M A$, et al. Obesity development during adolescence in a biracial cohort: the NHLBI growth and health study. Pediatrics. 2002;110(5):e54. [PubMed: 1241 5060]. https://doi.org/10.1542/peds.110.5.e54.

5. Freedman DS, Mei Z, Srinivasan SR, Berenson GS, Dietz WH. Cardiovascular risk factors and excess adiposity among overweight children and adolescents: the Bogalusa heart study. J Pediatr. 2007;150(1):12-7 e12. [PubMed: 17188605]

6. O'Brien PE, Sawyer SM, Laurie C, et al. Laparoscopic adjustable gastric banding in severely obese adolescents: a randomized trial. JAMA. 2010; 303(6):519-26 [PubMed: 20145228].

7. Treadwell JR, Sun F, Bruening W, et al. Bariatric surgery in pediatric patients. ECRI Institute; 2007.

8. Vanhala M, Vanhala P, Kumpusalo E, Halonen P, Takala J. Relation between obesity from childhood to adulthood and the metabolic syndrome: population based study. BMJ. 1998;317(7154):319-20. https://doi.org/10.113 6/bmj.317.7154.319.

9. Yitzhak A, Mizrahi S, Avinoach E. Laparoscopic gastric banding in adolescents. Obes Surg. 2006;16(10):1318-22. https://doi.org/10.1381/ 096089206778663823.

10. Alqahtani AR, Antonisamy B, Alamri $H$, Elahmedi M, Zimmerman VA. Laparoscopic sleeve gastrectomy in 108 obese children and adolescents aged 5 to 21 years. Ann Surg. 2012;256(2):266-73. https://doi.org/10.1097/ SLA.0b013e318251e92b.

11. Park JY, Song D, Kim YJ. Clinical experience of weight loss surgery in morbidly obese Korean adolescents. Yonsei Med J. 2014;55(5):1366-72. https://doi.org/10.3349/ymj.2014.55.5.1366.

12. Aridi HD, Fawal $H$, Shaghoury I, et al. Efficacy and safety of laparoscopic sleeve gastrectomy in adolescents. Bariatric Surg Pract Patient Care. 2016; 11(2):1-15.

13. Dargan D, Dolgunov D, Soe KT, Er P, Naseer F, Lomanto D, et al. Laparoscopic sleeve gastrectomy for morbidly obese adolescents in Singapore. Singap Med J. 2018;59(2):98-103. https://doi.org/10.11622/ smedj.2017086.

14. Franco RR, Ybarra M, Cominato L, Mattar L, Steinmetz L, Damiani $D$, et al. Laparoscopic sleeve gastrectomy in severely obese adolescents: effects on metabolic profile. Arch Endocrinol Metab. 2017;61(6):608-13. https://doi. org/10.1590/2359-3997000000310.

15. Mongol P, Chosidow D, Marmuse JP. Laparoscopic conversion of laparoscopic gastric banding to roux-en-Y gastric bypass: a review of 70 patients. Obes Surg. 2004;14:1349-53.

16. Christou NV, Look D, Maclean LD. Weight gain after short- and long-limb gastric bypass in patients followed for longer than 10 years. Ann Surg. 2006; 244(5):734-40. https://doi.org/10.1097/01.sla.0000217592.04061.d5.

\section{Publisher's Note}

Springer Nature remains neutral with regard to jurisdictional claims in published maps and institutional affiliations.

\section{Submit your manuscript to a SpringerOpen ${ }^{\circ}$ journal and benefit from:}

- Convenient online submission

- Rigorous peer review

- Open access: articles freely available online

- High visibility within the field

- Retaining the copyright to your article

Submit your next manuscript at $\boldsymbol{\nabla}$ springeropen.com 